\title{
Patients' Attitudes towards Complementary and Alternative Medicine: A Cross-Sectional Study among Hypertensive Patients in Baghdad, Iraq
} \author{
Dawood $^{5}$ \\ ${ }^{1}$ School of Pharmaceutical Sciences, Universiti Sains Malaysia, Malaysia \\ ${ }^{2}$ Professor of Social and Administrative Pharmacy, Universiti Sains Malaysia, Malaysia \\ ${ }^{3}$ Faculty of Pharmacy and Health Sciences, University of Baluchistan, Pakistan \\ ${ }^{4}$ Department of Pharmacy, Al-Mustafa University College, Iraq \\ ${ }^{5}$ Ministry of Science and Technology, Iraq
}

Inas Rifaat Ibrahim ${ }^{1 *}$, Mohamed Azmi Hassali², Fahad Saleem ${ }^{3}$, Haydar F Al Tukmagi ${ }^{4}$ and Omar Thanoon

Submission: April 02, 2018; Published: August 24, 2018

*Corresponding author: Inas Rifaat Ibrahim, School of Pharmaceutical Sciences, Universiti Sains Malaysia, Malaysia; Email: azmihassali@gmail.com

\begin{abstract}
The use of complementary and alternative medicine (CAM) in the management of hypertension (HTN) is evident. This necessitates the need to investigate the prevalent attitudes that drive the patient to pursue this practice. This study aimed to assess HTN patients' attitudes towards CAM; patient-doctor communication about CAM and attitudes towards disclosing it to the physician. A cross-sectional study was conducted among HTN patients attending out-patient clinics of two major teaching hospitals in Baghdad, Iraq. A convenience sampling method was adopted for the recruitment, and a validated CAM-attitude questionnaire was used for gathering the information. CAM was used by $65.5 \%$ of respondents. A significant difference in patients' attitudes towards CAM was found between CAM-users (mean=4.34+1.67, median=5.0) versus non-users ( mean=1.31+0.93, median=1.0), $\mathrm{P}<0.001$. The highest favorable attitude towards CAM was seem among females patients $(\mathrm{mean}=3.73+2.22$, median=4.0, $\mathrm{P}<0.001$ ) and patients holding an elementary level of education (mean=5.01+1.7, median $=5.0, \mathrm{P}<0.001)$. A poor patient-doctor communication about CAM was found and a non-favorable attitude towards disclosing CAM to the physician was detected among users of this practice. In addition, an inverse relationship was found between attitudes towards CAM and attitudes towards disclosing it to the physician (rho=-0.355, $\mathrm{P}<0.001$ ). In conclusion, CAM was a common practice among Iraqi HTN patients. Users of CAM showed a favorable attitude towards it which was associated with gender and patient's educational level. Patient-doctor communication about CAM was poor and characterized by poor attitudes towards disclosing it to the physician. An inverse relationship between attitudes towards CAM and attitudes towards disclosing it to the physicians was detected.
\end{abstract}

Keywords: Complementary medicine; Attitudes; Disclosing CAM; Iraq; Hypertension

Abbreviations: CAM: Complementary and Alternative Medicine; HTN: Management of Hypertension; IMOH: Iraqi Ministry of Health; CAMAQ: CAM-Attitudes Questionnaire; NCCIM: National Centre for Complementary and Integrative Medicine; SPSS: Statistical Package for Social Science; ROS: Reactive Oxygen Species

\section{Introduction}

The trend of using CAM in the control of blood pressure is growing. CAM constitutes therapies that are not classified as standard pharmacological treatment [1]. It contains domains of healing resources linked with individual beliefs and cultural treatment practices like the use of crude herbs, meditation, massage, biofeedback, reflexology, acupuncture, spirituality, homeopathy, hypnosis, and cupping. Notably, therapies of CAM are differ according to the cultural diversity around the world. Information on the guidelines for preparation, doses, and dispensing is still insufficient and inconvenient [2]. Previous studies have reported the use of variety of herbal, non-herbal, and other approaches in the control of blood pressure [3-6]. The rate of using CAM in the management of blood pressure was as high as $85.7 \%$ [7]. However, the difference in the definition of CAM from country to country make this rate varied from study to study.

The considerable use of CAM among HTN patients gives an indication of a distinct attitude towards it. Previous studies have found that users of CAM were characterized by a positive attitudes towards this practice [8-10]. Patient's attitude towards 
any treatment is the overall assessment and evaluation of patient's beliefs and the outcome associated with that treatment [11]. However, it remains unclear what attitude drives the HTN patient to choose and maintain the use of CAM. Several notions have been proposed that collectively explained patient's attitude towards CAM. These include a belief in nature and natural remedy [12]. Adherents to natural remedy hold a strong belief in the effectiveness of nature to cure the illness; as well as, a belief that natural composition is always free from any side effect resulted from the industrialized treatment [10]. Another notion proposed that the favorable attitude towards CAM is a factor of psychological agreement between patient's philosophy about CAM and the concept of health [13]. Rejection of science (anti-science feeling) was found as another contributing factor in the favorable attitude towards CAM. Users of CAM tend to perceive that health as a comprehension of the body parts which are intimately interconnected. Hence they reject the scientific authority and hold a holistic opinion of health to cure from illness [14]. Moreover, a belief in personal ability in contributing to good health was found to be related with the positive attitude towards CAM [15]. This means that faith in being able to contribute to the health rather than referring it to the doctors or other health professionals may affect the behavior of seeking a treatment.

The steady gain in using CAM was explained as a reason of dissatisfaction with the standard treatment [16]. However, the model suggested by Siahpush confirmed that discontent with patient-doctor communication was the significant contributor in searching CAM; whereas, dissatisfaction with the medical treatment itself was not a significant predictor [17]. This motivated the researchers to investigate patients' disclosure of CAM to the health professionals which was found to be very poor $[2,7,18]$. As such, the current study will be more effective in exploring an important issue related to patient-doctor communication about CAM which is the attitudes towards disclosing CAM to the physicians.

A recent qualitative scenario from Iraq reported that CAM is prevalent among HTN characterized by using some kinds of herbs; cupping; reflexology; and acupuncture in the control of blood pressure [19]. Hence, the question that come into investigation here is what the attitude and the associated factors underlying Iraqi patient's motivation to use CAM in the control of blood pressure. This study was sought to determine the use of CAM among HTN population; assess the prevalent attitudes towards CAM and the associated factors; assess patient-doctor communication about CAM and attitudes towards disclosing it to the doctor; and find the relationship between patients' attitudes towards disclosing CAM to the doctor and attitudes towards CAM.

\section{Methods}

\section{Study design}

A cross sectional study was conducted at outpatient clinics of two major teaching hospitals in Baghdad, the capital of Iraq.
The duration of the study extended from Oct 2015 to July 2016. Baghdad is divided by the river Tigris into two parts Karkh (the west part) and Rusafa (the east part). Therefore; Ibn Al-Nafees hospital (from Rusafa side) and Al-Karama hospital (from Karkh side) were chosen as the study setting. Both hospitals are major teaching and public hospitals in Baghdad affiliated to the Iraqi Ministry of Health (IMOH) and providing healthcare at a very low charge. The two hospitals are well-maintained with various specialties of in-patient and out-patient services. They were selected to

a) Allow a fair representation of hypertensive patients from the city

b) To adhere to the instructions of $\mathrm{IMOH}$ that do not permit conducting any type of research in more than two hospitals of the city and

c) The outpatient clinics of both hospitals are frequently visited by a considerable number of patients every day.

A convenience sampling technique was used for recruiting HTN patients. A validated CAM-attitudes questionnaire (CAMAQ) was used for the purpose of gathering the data. Ethical approval to conduct the study was obtained from IMOH (\#74633). The study was conducted upon patients' approval, and after obtaining a signed informed consent. Monetary payment or other forms of compensation were not offered.

Sample size: Calculation of the sample size was based on the prevalence sampling technique [20]. Prevalence of hypertension in Iraq is $38.5 \%$, a confidence interval of $95 \%$, an allowable margin of error $5 \%$. Assuming dropout rate of $20 \%$; the target sample size was 436 patients.

Participants: A total of 218 patients from each selected hospital were invited to insure a fair representation of crosssectional sample. Where patients were more than 18years old; both genders; diagnosed with hypertension for at least one year; and not too ill to communicate with the researcher. Newly diagnosed patients were not included to avoid the confusion that might be understood as suggesting more therapeutic options and prevent creating additional stress that often accompaniesa new diagnosis. Patients were informed about the study objectives and protocols prior to participation. They were also assured that their answers would be kept confidential, and no information that could reflect their identity will be disclosed.

Assessment tool: The four sections CAMAQ was developed based on previous literatures to achieve the aim of the study. The first section contained the demographic characteristics (gender, age, education, marital status, monthly income, duration of hypertension, and co-morbidity). The second section encompasses questions about the use of CAM. Participants were questioned to report CAM usage by noting on a list of different CAM products if they had used in the past or currently using it to control their blood pressure. The list of CAM products was based on a standard classification by the National Centre 
for Complementary and Integrative Medicine (NCCIM) [1]. Questions of the first and second sections were either multiple choice responses (multiple options could be ticked) or openended answers filled by the participants. Section three of the questionnaire encompasses assessment of patient's attitudes towards CAM. Items of this domain reflected the following dimensions: effectiveness, protection, safety, naturalist, personal responsibility, and philosophy of health. These dimensions were identified from previous literatures as potentially assessing attitude towards CAM $[10,15,21]$. Responses to this domain were measured using "Yes", "No", and "Do not know" answers. The last section, section four, contained questions to assess patient-doctor communication about CAM and the attitudes towards disclosing CAM to the physician. Questions of this part were obtained and amended from previous literatures $[7,18]$. The domain attitudes towards disclosing CAM use was also measured using "Yes", "No", and "Do not know" answers. Face validity of the questionnaire was assessed by consulting a panel of experts for reasonableness, appropriateness, and sequence of the items. While content validity was established by adopting the same validated questions of the previous mentioned literatures. Reliability analysis of the domains "attitude towards CAM" and "attitude towards disclosing CAM" revealed a good internal consistency (Cronbach alpha) of 0.68 and 0.69 , respectively.

\section{Statistical Analysis}

The collected data was coded and entered to the program Statistical Package for Social Science version 16 (SPSS Inc., Chicago, USA) for statistical analysis. Descriptive statics were presented as frequencies, percentages, mean (+SD), and median (IQR). For subsequent analysis, respondents were categorized as either CAM users or non-users. Regarding the domain attitudes towards CAM, a dichotomous measure was created from the responses of its eight items. That is coded 1 for agreement response and 0 otherwise. In consequence, this dichotomous coding can be envisioned as indication of agreement to the items of the domain. The overall higher score would be indicative of favorable attitudes [22]. The same dichotomous measure was created for the five items under the domain "attitudes towards disclosing CAM to the physician". A favorable attitude towards this domain is a reflection of an overall higher score. Users of CAM and non-users were compared in their attitudes by their agreements proportion to each item. In addition, their overall scores on both domains were compared by Mann-Whitney U test to detect the significant differences between them. A priori level of significance was accepted at 0.05. Further, Mann-Whitney and Kruskal Wallis tests were used to detect the significant differences in patients' characteristics on attitudes towards CAM. Added to this, Post-hoc analysis was performed to compare the significant effect among the three groups of patient's educational level. For this type of analysis, a Bonferroni adjustment to the alpha value of 0.05 was applied to control for type 1 error. The adjustment was done by dividing the alpha value by 3 (the number of tests that used to assess the significant differences among three subgroups). In consequence, a stricter alpha value of 0.017 was adopted. Lastly, Spearman rank order coefficient was used to assess the relationship between the two domains "attitudes towards CAM" and "attitudes towards disclosing CAM to the physician".

\section{Result}

\section{Characteristics of respondents}

A total of 400 valid responses were obtained recorded a response rate of $91.7 \%$. The values of systolic blood pressure reading ranged from 155 to $230 \mathrm{mmHg}$ (mean=187.5+15.9). While, for diastolic blood pressure ranged from 80 to 110 $($ mean=93.4+5.6). The percentage of male was slightly higher $(55.2 \%)$ than that of females. Age of respondent ranged from 35 to 84 years old; patients > 65 years recorded the highest percentage $(54.8 \%)$. Other highest characteristics were intermediate level of education (41.8\%); intermediate monthly income level (41.2\%); patients who were in a relation $(61.0 \%)$; patients with HTN for more than five years (56.5\%); and patients with co-morbidity (72.5\%). Details of patients' characteristics are presented in Table 1.

Table 1: Demographic characteristics of respondents.

\begin{tabular}{|c|c|c|}
\hline \multicolumn{2}{|c|}{ Characteristics } & \multirow{2}{*}{$\frac{\mathbf{n}(\mathbf{\%})[\mathbf{N}=\mathbf{4 0 0}]}{179(44.8)}$} \\
\hline \multirow{2}{*}{ Gender } & Female & \\
\hline & Male & $221(55.2)$ \\
\hline \multirow{2}{*}{ Age groups in years } & $<65$ & $181(45.3)$ \\
\hline & $\geq 65$ & $219(54.8)$ \\
\hline \multirow{3}{*}{ Educational levels } & Elementary & $140(35.0)$ \\
\hline & Intermediate & $167(41.8)$ \\
\hline & High & $93(23.2)$ \\
\hline \multirow{3}{*}{ Income in US $\$$} & $<500$ & $128(32.0)$ \\
\hline & $500-1000$ & $165(41.2)$ \\
\hline & $>1000$ & $107(26.8)$ \\
\hline \multirow{2}{*}{ Marital status $^{\mathrm{b}}$} & In a relation & $246(61.5)$ \\
\hline & Not in a relation & $154(38.5)$ \\
\hline \multirow{2}{*}{ Duration of HT in years } & $\leq 5$ & $174(43.5)$ \\
\hline & $>5$ & $226(56.5)$ \\
\hline \multirow{2}{*}{ Comorbidity } & Yes & $290(72.5)$ \\
\hline & No & $110(27.5)$ \\
\hline
\end{tabular}

aEach 1 US Dollar = 1164 Iraqi Dinar.

bIn a relation involved the married respondents; while, not in a relation involved the single, divorced, and widow respondents.

\section{The use and attitudes towards CAM}

The use of CAM was recognized by around two thirds (65.5\%) of respondents. Different products of CAM were used by HTN patients to control the blood pressure. These were herbs; cupping ("Alhijama" in Arab society); reflexology; acupuncture; and some dietary supplements. The most used herbs were garlic; flaxseeds; dried lime; rosella tea; green tea; saffron; ginger; peppermint tea; and chines herbs. 
Table 2: Differences in attitudes towards CAM between CAM users vs. non-users.

\begin{tabular}{|c|c|c|c|c|c|c|c|}
\hline & \multirow{2}{*}{ Statements } & \multicolumn{3}{|c|}{ CAM Users $(n=262) n(\%)$} & \multicolumn{3}{|c|}{ CAM Non-Users $(n=138) n(\%)$} \\
\hline & & Yes & No & Don't know & Yes & No & Don't know \\
\hline \multicolumn{2}{|c|}{$\begin{array}{l}\text { CAM is effective treatment for the control of blood } \\
\text { pressure }\end{array}$} & $166(63.5)$ & $65(24.7)$ & $31(11.8)$ & $26(18.8)$ & $62(44.9)$ & $50(36.2)$ \\
\hline \multicolumn{2}{|c|}{$\begin{array}{l}\text { The efficacy of CAM is equivalent or better than } \\
\text { conventional treatment in my disease }\end{array}$} & $124(47.3)$ & 70 (26.7) & $68(26.0)$ & $30(21.7)$ & $50(36.2)$ & $58(42.0)$ \\
\hline \multicolumn{2}{|c|}{$\begin{array}{l}\text { CAM protects hypertensive patients from } \\
\text { cardiovascular problems }\end{array}$} & $128(48.9)$ & $51(19.5)$ & $83(31.7)$ & $0.0(0.0)$ & $71(51.4)$ & $67(48.6)$ \\
\hline \multicolumn{2}{|c|}{ CAM is completely safe } & $196(74.8)$ & $50(19.1)$ & $16(6.1)$ & $23(16.7)$ & $62(44.9)$ & $53(38.4)$ \\
\hline \multicolumn{2}{|c|}{ CAM does not interact with the conventional medicine } & $224(85.5)$ & $14(5.3)$ & $24(9.2)$ & $20(14.5)$ & $53(38.4)$ & 65 (47.1) \\
\hline \multicolumn{2}{|c|}{$\begin{array}{l}\text { CAM is more natural form of healing than conventional } \\
\text { medicine }\end{array}$} & $144(55.0($ & $65(24.8)$ & $53(20.2)$ & $46(33.3)$ & $70(50.7)$ & $22(15.9)$ \\
\hline \multicolumn{2}{|c|}{$\begin{array}{l}\text { CAM enables me to take more active part in } \\
\text { maintaining my health }\end{array}$} & $155(59.2)$ & $43(16.4)$ & $64(24.4)$ & $36(26.1)$ & $45(32.6)$ & 57 (41.3) \\
\hline \multicolumn{2}{|c|}{$\begin{array}{l}\text { Health is about harmonizing your body, mind, and } \\
\text { spirit }\end{array}$} & $238(59.5)$ & $30(7.5)$ & $132(33.0)$ & $22(15.9)$ & $100(72.5)$ & $16(11.6)$ \\
\hline \multirow{2}{*}{ Total Score } & Mean (+SD) & \multicolumn{3}{|c|}{$4.34(1.67)$} & \multicolumn{3}{|c|}{$1.31(0.93)$} \\
\hline & Median (IQR) & \multicolumn{3}{|c|}{$5.0(0-3)^{*}$} & \multicolumn{3}{|c|}{$1.0(0-1)$} \\
\hline
\end{tabular}

*Mann-Whitney $U$ test detected a significance level of $P<0.001$.

Responses to the domain "attitudes towards CAM" revealed a distinct favorable attitude towards some perceived characteristics of CAM. These attitudes were recognized considerably among patients who were using CAM to control their elevated blood pressure as shown in Table 2. The first two items of the domain reflected patients' considerations towards effectiveness of CAM. The proportion of patients' agreements to the first (63.5\%) and second (47.3\%) items were higher among CAM users than non-users. The third item reflects patients' considerations towards the ability of CAM in protecting HTN patients from the cardiovascular consequences. Nearly half $(48.9 \%)$ of CAM users responded with agreements to this item. However, none of CAM non-users agreed to this item. The dimension safety of CAM was reflected by patients' responses to the fourth and fifth items of the domain. It was noticed that three quarters $(74.8 \%)$ and more than three quarters $(85.5 \%)$ of CAM users showed their agreements to the fourth and fifth items respectively. In contrast, a very low percentages of agreements were reported by nonusers of CAM on the same items. The sixth item of the domain reflected patients' believes in the natural therapy. More than half $(55.0 \%)$ of CAM users were in agreements that CAM is more natural form of healing than conventional medicine. While, nonusers of CAM reported a low percentage of agreements (33.3\%) on this item. Concerning the dimension individual responsibility (item number seven); more than half $(59.2 \%)$ of CAM users agreed that CAM enables them to take more active part in maintaining the health. however, the agreement percentages of CAM non-users on this item was very low (26.1\%). In the last item of the domain that reflected patients' philosophy of health; more than half of CAM users (59.5\%) were also in agreement that health is a about harmonizing the body, mind, and spirit. However, a very low percentage (15.9\%) was reported from nonusers of CAM on the same item.

Table 3: The differences of patient's characteristics in attitudes towards CAM

\begin{tabular}{|c|c|c|c|c|}
\hline \multirow{2}{*}{\multicolumn{2}{|c|}{ Characteristics }} & \multicolumn{2}{|c|}{ Attitudes towards CAM } & \multirow{2}{*}{$P$ value } \\
\hline & & Mean (+SD) & Median & \\
\hline \multirow{2}{*}{ Gender } & Female & $3.73(2.22)$ & 4.0 & \multirow{2}{*}{$0.000^{*}$} \\
\hline & Male & $2.94(1.83)$ & 3.0 & \\
\hline \multirow{2}{*}{ Age groups in years } & $<65$ & $3.14(2.04)$ & 3.0 & \multirow{2}{*}{0.162} \\
\hline & $\geq 65$ & $3.42(2.07)$ & 3.0 & \\
\hline \multirow{3}{*}{ Educational levels } & Elementary & $5.01(1.71)$ & 5.0 & \multirow{3}{*}{$0.000^{* *}$} \\
\hline & Intermediate & $2.83(1.60)$ & 3.0 & \\
\hline & High & $1.55(1.14)$ & 1.0 & \\
\hline \multirow{3}{*}{ Income in US $\$$} & $<500$ & $3.76(2.2)$ & 4.0 & \multirow{3}{*}{0.429} \\
\hline & $500-1000$ & $3.58(2.02)$ & 4.0 & \\
\hline & $>1000$ & $2.31(1.56)$ & 2.0 & \\
\hline
\end{tabular}


Journal of Complementary Medicine \& Alternative Healthcare

\begin{tabular}{|c|c|c|c|c|}
\hline \multirow{2}{*}{ Marital status $^{\mathrm{b}}$} & In a relation & $2.93(2.12)$ & 2.0 & 0.113 \\
\cline { 2 - 5 } & Not in a relation & $2.70(2.07)$ & 2.0 & \\
\hline \multirow{2}{*}{ Duration of HT in years } & $\leq 5$ & $3.25(2.20)$ & 3.0 & \multirow{2}{*}{0.561} \\
\cline { 2 - 4 } & $>5$ & $3.33(1.94)$ & 3.0 & \multirow{2}{*}{0.161} \\
\cline { 2 - 5 } Comorbidity & Yes & $3.38(2.031)$ & 3.0 & \\
\cline { 2 - 5 } & No & $3.06(2.10)$ & & \\
\hline
\end{tabular}

${ }^{a}$ Each 1 US Dollar=1164 Iraqi Dinar.

bIn a relation involved the married respondents; while, not in a relation involved the single, divorced, and

The total score of the domain "attitudes towards CAM" for CAM users extended from zero to 7; while it was ranged from zero to 4 for CAM non-users. The mean of the total score for CAM users was fairly higher $(4.34+1.67)$ than that of CAM nonusers $(1.31+0.93)$. The medians were statistically different from each other by Mann-Whitney $\mathrm{U}$ test, $\mathrm{P}<0.001$. That is, patients' who are using CAM in the management of HTN have a favorable attitude toward CAM than non-users.

The analysis also assessed whether the score of attitude towards CAM was a function of patients' characteristics as seen in Table 3. Female patients were higher in their favorable attitudes towards CAM (mean=3.73+2.22) than male patients (mean=2.94+1.83). A significant difference between genders was obtained by Mann-Whitney U test, $P<0.001$. Patients' with elementary level of education had favorable attitudes $($ mean $=5.01+1.71)$ greater than intermediate $(2.83+1.60)$ and high $(1.55+1.14)$ levels of education. The medians were statistically different among the three levels by Kruskal-Wallis test, $\mathrm{P}<0.001$. Post-hoc analysis of patient's educational levels

showed that the medians were significantly different among all the three subgroups. Patients' with elementary level of education had more favorable attitudes towards CAM higher (median=5.0) than patients' with intermediate (median=3.0) and high (median=1.0) levels; $\mathrm{P}<0.017$. Furthermore, patients' with intermediate level of education had more favorable attitudes towards CAM (median=3.0) than patients with high (median=1.0) level of education, $\mathrm{P}<0.017$. There were no effect of age, income, marital status, duration of HTN, and co-morbidity on attitudes towards CAM scores.

\section{Patients-doctor communication about CAM}

Patients were questioned whether they had been assessed by their doctors about CAM usage. Notably, all of them reported that they had never been asked by their doctors about any treatment with CAM. They were then questioned whether they had disclosed their CAM use to the doctor. Responses showed that very few $(11.5 \%, \mathrm{n}=46)$ of CAM users had told their doctors about their use of CAM to control the blood pressure.

Table 4: Patient's attitudes towards disclosing CAM to the physician

\begin{tabular}{|c|c|c|c|c|}
\hline \multirow{2}{*}{ Variables } & \multicolumn{2}{|c|}{ Total Score } & \multirow{2}{*}{ rho } & \multirow{2}{*}{$P$ value } \\
\hline & Mean (+SD) & Median (IQR) & & \\
\hline Attitudes towards disclosing CAM use to the doctor & $2.51(+1.36)$ & $2.0(0-5)$ & \multirow{2}{*}{-0.355} & \multirow{2}{*}{$0.000^{*}$} \\
\hline Attitudes towards using CAM & $3.30(+2.05)$ & $3.0(0-3)$ & & \\
\hline
\end{tabular}

*Mann-Whitney $\mathrm{U}$ test detected a significance level of $\mathrm{P}<0.001$.

Table 5: The relationship between patient's attitudes towards disclosing CAM use to the doctor and the attitudes towards using CAM rho: Spearman rank order coefficient; * $\mathrm{P}<0.05$.

\begin{tabular}{|c|c|c|c|c|c|c|c|}
\hline \multirow{2}{*}{\multicolumn{2}{|c|}{ Statements }} & \multicolumn{3}{|c|}{ CAM Users (n=262) n (\%) } & \multicolumn{3}{|c|}{ CAM Non-Users ( $n=138)$ n (\%) } \\
\hline & & Yes & No & Don't know & Yes & No & Don't know \\
\hline \multicolumn{2}{|c|}{ It is important to ask the doctor about CAM. } & $23(8.8)$ & $191(72.9)$ & $48(18.3)$ & $112(81.2)$ & $2(1.4)$ & $24(17.4)$ \\
\hline \multicolumn{2}{|c|}{ The doctor has a good information about CAM. } & $22(8.4)$ & $140(53.4)$ & $100(38.2)$ & $110(79.7)$ & $8(5.8)$ & $20(14.5)$ \\
\hline \multicolumn{2}{|c|}{ The doctor will reject my treatment with CAM. } & $131(50.0)$ & $28(10.7)$ & $103(39.3)$ & $56(40.6)$ & $25(18.1)$ & $57(41.3)$ \\
\hline \multicolumn{2}{|c|}{$\begin{array}{l}\text { The doctor did not have enough time to discuss about } \\
\text { CAM. }\end{array}$} & $217(82.8)$ & $30(11.5)$ & $15(5.7)$ & $108(78.3)$ & $30(21.7)$ & $0(0.0)$ \\
\hline \multicolumn{2}{|c|}{ I found it difficult to talk to my doctor about CAM. } & $129(49.2)$ & $118(45.0)$ & $15(5.7)$ & $27(19.6)$ & $106(76.8)$ & $5(3.6)$ \\
\hline \multirow{2}{*}{ Total Score } & Mean (+SD) & \multicolumn{3}{|c|}{$1.95(1.05)$} & \multicolumn{3}{|c|}{$3.58(1.23)$} \\
\hline & Median (IQR) & \multicolumn{3}{|c|}{$2.0(0-2)^{*}$} & \multicolumn{3}{|c|}{$4.0(0-1)$} \\
\hline
\end{tabular}

Analysis were also performed to assess patients' attitudes towards disclosing CAM to the doctor as shown in Table 4. Patients' responses to the first item of this domain showed that very few proportion (8.8\%) of CAM users agreed that asking the doctor about CAM is important. In contrary, more than three quarters of CAM non-users responded with their agreement to this item. In the second item, responses showed that very few proportion $(8.4 \%)$ of CAM users agreed that the doctor has good information about CAM. Whereas; more than three quarters of CAM non-users showed agreement on the same item. In the 
third item, half of CAM users responded that the doctor will reject their usage of CAM; however less than half $(40.6 \%)$ of CAM non-users showed agreement on this item. Notably, both types of respondents (users and non-users) reported with high percentages their agreements on the fourth item of the domain. The majority of CAM users (82.8\%) agreed that the doctor did not have enough time to discuss about CAM, and more than three quarters $(78.3 \%)$ of CAM non-users showed the same response. Lastly, less than half $(49.2 \%)$ of CAM users found it difficult to talk to their doctors about CAM. However, a very low percentage (19.6\%) of CAM non-users showed agreement on this item.

Notably, attitudes towards disclosing CAM use to the physician was significantly correlated with attitudes towards using CAM as seen in Table 5. A negative medium correlation was found via Spearman rank order coefficient $(\mathrm{rho}=-0.35, \mathrm{P}<0.001)$. This means that increased attitudes towards using CAM is associated with deceased attitudes in disclosing this practice to the doctor.

\section{Discussion}

The study revealed an important information within the area of how attitudes towards CAM drive the HTN patients to pursue this practice in the control of blood pressure. Despite previous studies has discussed attitudes towards CAM among university students and healthcare providers; the present study involved HTN patients recruited from a hospital setting. Hence, this study was capable of addressing attitudes towards CAM permitting better generizability to HTN patients seeking CAM for prevention and treatment. Up to this date, information explored from this scenario is the first of its kind from Iraq.

The study showed that CAM users were in favorable attitudes towards this practice; whereas, CAM non-users were not. This was in line with previous studies that conducted in the developed and developing countries [10,15,23]. Analysis of the dimensions that composed this domain (attitudes towards CAM) showed that CAM users were more likely to consider this practice as effective treatment in the control of blood pressure. Previous investigations also reported that the use of CAM is often underpinned by a strong belief in effectiveness of CAM for various illness[9,24]. Meanwhile, respondents also perceived that CAM efficacy is equivalent or better than the standard conventional treatment. This perception added evidence to the previous reported data where CAM perceived to work in the same way and sometimes better than the standard treatment [25]. A belief that CAM treatment protects the HTN patients from cardiovascular consequences was also predominant among CAM users. This may explain why HTP patients maintain the use of CAM alongside their conventional treatment as endorsed previously $[24,26]$. Interestingly, some species of herbs (flavonoids as an example) are able to protect the heart from the damaging effect of reactive oxygen species (ROS) contributing to the antioxidant defense mechanism [27]. The analysis also showed that a large segment of CAM users perceived CAM as safe products and not interact with the conventional treatment. Variation in the safety and CAM-drug interaction is yet a questionable issue of high concern [22]. Pursuing CAM especially ingestion of herbs without proper counselling may indirectly affect the treatment plane through interactions with the components of the pharmacological treatment [18]. Safety of CAM is still a global concern especially when consumed in case of chronic diseases where multiple drug therapy is required $[4,28]$. Serious interactions are reported between cardiovascular treatment and some consumed herbs for HTN like hawthorn, ginger, green tea, and peppers [29,30]. The only evident fact is that CAM with encouraging benefits and safety for HTN condition encompasses garlic, biofeedback, yoga, and message [31-33]. The perception of "natural effect" was also prevalent among users of CAM in this scenario. Attitudes towards using CAM have always been linked with the belief that CAM is derived from nature resulting in natural cure from illness without toxic effect to human body $[2,13]$. The natural composition of CAM was found as the main reason of attraction to this practice and often linked with the cultural beliefs of the society $[4,13,34]$. In addition, a philosophy of personal responsibility to take part in maintaining the health was also prevalent among CAM users. Personal responsibility for good health was assigned for the favorable attitudes towards CAM $[18,15]$. The last dimension of attitudes towards CAM revealed that users of this practice considered health as a harmony between the body, mind and spirit. A philosophy that health is the intimate interconnection between body parts, mind and the spirit was indicated as a significant predictor of favorable attitudes towards CAM $[8,17]$. Based on this result, it could be explained why those engaged with CAM treatment showed high agreements to the attitude items that reflect the predominant believes pertaining CAM; whereas, those not pursuing CAM showed non-agreements to the attitudes items.

One of the largest subgroup of respondents holding favorable attitudes towards CAM were female and patients with elementary level of education. Other demographic factors did not contribute to the differences in attitudes towards CAM. This finding was contradicted with the models suggested previously where age of patients was the only predictor of positive attitudes towards CAM $[8,10]$. This contradictory result may be attributed to the differences in the population sample where university students were recruited in previous studies in assessing attitudes towards CAM. Further exploration is needed in this regard.

It was not surprising that patients of this study were never assessed by their physicians about the use of CAM. Information obtained from previous studies often revealed lack of patient's assessment within the context of CAM $[5,6,9]$. At the same time, a considerable number of participants had not disclosed their use of CAM to the physician. Similar finding was often reported from related researches [2,7,35-36]. This revealed a lack of awareness of patients and health professionals about the dangerous associated with the unsupervised use of CAM. Serious consequences were noted due the concomitant use of 
CAM (especially herbals) with the standard pharmacological treatment like missed diagnoses, adverse effect, toxicity, and failure of the HTN management plane [29,30,37]. This fact necessitate the need to obtain a carful patient's history on CAM usage during the routine clinical assessment. This kind of information is important for health care providers to give the proper advice in the management of HTN; as well as, preventing the risk of developing cardiovascular consequences.

Notably in this study, users of CAM showed poor attitudes towards disclosing CAM use to the health professionals. A large segment of CAM users denied the importance of asking the doctor about CAM and disagreed that the doctor has a good information related to CAM. Studies have suggested that non-favorable attitudes towards disclosing CAM is associated with a rejection of authority and a belief in personal responsibility toward health $[8,38]$. However, CAM users were in agreement that the doctor will reject their self-practice of CAM. Fear of doctor-rejection and disapproval of CAM usage were often reported as reasons of non-disclosure $[2,9,38]$. Noticeably, a considerable number of both users and non-users of CAM were in agreement that doctors did not have enough time for counselling about CAM. Insufficient consultation time was found to be a barrier for many patients to disclose their use of CAM to the physicians [39-40]. Lack of interest shown by the doctors in assessing their patients about CAM was found to be problematic in the communication flow between the patients and the health professionals [2,39]. In general, the interest with CAM among health professionals is not encouraging. It was found that they prefer the standard validated treatment, and most of them have a concern towards the safety or efficacy of CAM therapy [41-42]. Hence, the disparate attitudes between patients and their physicians may reduce the patients' motives to disclose CAM usage to the health professionals.

The correlation analysis of this study has revealed an inverse relationship between patients' attitudes towards disclosing CAM to the health professionals and the attitudes towards CAM. That is, patients with favorable attitudes towards CAM are less motivated to disclose this practice to their physicians. In consequence, this may impose the risk of inaccurate diagnosis and serious CAM-drug interactions. Therefore, an open dialog with the patients is encouraged as long as patients are usually consulting physicians who are the best informed in the field of medical treatment.

\section{Conclusion}

The use of CAM for the control of blood pressure was a common practice among Iraqi HTN patients. A favorable attitude towards CAM was noted among users of this therapy and was associated with gender and patient's educational level. Poor patient-doctor communication about CAM was noted characterized by low disclosure of CAM usage to the physicians. Added to this, poor attitudes towards disclosing CAM use was prevalent among users of CAM. Moreover, patient's attitude towards disclosing CAM to the physician was inversely correlated with their attitudes towards this practice. Therefore, it became necessary that health professionals must inquire their patients about the self-use of CAM to prevent the problems associated with CAM-drug interaction and failure of therapeutic management of hypertension.

\section{Acknowledgment}

The authors would like to thank all participants in Iraq for their time and responses to this study.

\section{References}

1. NCCIH (2016) Complementary, alternative, or integrative health: what's in a name?

2. Kretchy IA, Owusu-Daaku F, Danquah S (2014) Patterns and determinants of the use of complementary and alternative medicine: a cross-sectional study of hypertensive patients in Ghana. BMC complementary and alternative medicine 14(1): 44.

3. Yeh GY, Davis RB, Phillips RS (2006) Use of complementary therapies in patients with cardiovascular disease. Am J Cardiol 98(5): 673-680.

4. Amira OC, Okubadejo NU (2007) Frequency of complementary and alternative medicine utilization in hypertensive patients attending an urban tertiary care centre in Nigeria. BMC Complement Altern Med $7(1): 30$.

5. Omeish AF, Abbadi W, Ghanma IM, Drabaa Z, Botoosh FA, et al. (2011) Hospital-based study on the use of herbal medicine in patients with coronary artery disease in Jordan. J Pak Med Assoc 61(7): 683-687.

6. Hughes GD, Aboyade OM, Clark BL, Puoane TR (2013) The prevalence of traditional herbal medicine use among hypertensives living in South African communities. BMC Complement Altern Med 13(1): 38.

7. Ali-Shtayeh MS, Jamous RM, Jamous RM, Salameh NM (2013) Complementary and alternative medicine (CAM) use among hypertensive patients in Palestine. Complement Ther Clin Pract 19(4): 256-263.

8. O'Callaghan FV, Jordan N (2003) Postmodern values, attitudes and the use of complementary medicine. Complement Ther Med 11(1): 28-32.

9. Singh V, Raidoo DM, Harries CS (2004) The prevalence, patterns of usage and people's attitude towards complementary and alternative medicine (CAM) among the Indian community in Chatsworth, South Africa. BMC Complement Altern Med 4(1): 3.

10. Huber R (2004) Experience and attitudes towards CAM-a survey of internal and psychosomatic patients in a German university hospital. Alternative therapies in health and medicine 10(1): 32.

11. Sable MR, Schwartz LR, Kelly PJ, Lisbon E, Hall MA, et al. (2006) Using the theory of reasoned action to explain physician intention to prescribe emergency contraception. Perspectives on sexual and reproductive health 38(1): 20-27.

12. Siahpush M (1999) Postmodern attitudes about health: a populationbased exploratory study. Complementary therapies in medicine 7 (3): 164-169.

13. Astin JA (1998) Why patients use alternative medicine: results of a national study. JAMA 279(19): 1548-1553.

14. Siahpush M (1999) Why do people favour complementary medicine. Aust NZ J Publ Heal 23(3): 266-271.

15. McFadden KL, Hernández TD, Ito TA (2010) Attitudes toward complementary and alternative medicine influence its use. Explore (NY) 6(6): 380-388.

16. Furnham A, Forey J (1994) The attitudes, behaviors and beliefs of 
patients of conventional vs. complementary (alternative) medicine. J Clin Psychol 50(3): 458-469.

17. Siahpush M (1998) Postmodern values, dissatisfaction with conventional medicine and popularity of alternative therapies. Journal of Sociology 34(1): 58-70.

18. Wazaify M, Alawwa I, Yasein N, Al-Saleh A, Afifi FU, et al. (2013) Complementary and alternative medicine (CAM) use among Jordanian patients with chronic diseases. Complement Ther Clin Pract 19(3): 153-157.

19. Ibrahim IR, Hassali MA, Saleem F, Al Tukmagi HF (2016) A qualitative insight on complementary and alternative medicines used by hypertensive patients. J Pharm Bioallied Sci 8(4): 284-288.

20. Naing L, Winn T, Rusli B (2006) Practical issues in calculating the sample size for prevalence studies. Archives of orofacial Sciences 1(1): $9-14$.

21. Shorofi SA, Arbon P (2010) Complementary and alternative medicine (CAM) among hospitalised patients: an Australian study.

Complement Ther Clin Pract 16(2): 86-91.

22. Furlow ML, Patel DA, Sen A, Liu JR (2008) Physician and patient attitudes towards complementary and alternative medicine in obstetrics and gynecology. BMC Complement Altern Med 8(1): 35.

23. Tindle HA, Davis RB, Phillips RS, Eisenberg DM (2005) Trends in use of complementary and alternative medicine by US adults: 1997-2002. Altern Ther Health Med 11(1): 42-49.

24. Nuwaha F, Musinguzi G (2013) Use of alternative medicine for hypertension in Buik we and Mukono districts of Uganda: a cross sectional study. BMC complementary and alternative medicine 13(1): 301

25. Shafiq N, Gupta M, Kumari S, Pandhi P (2003) Prevalence and pattern of use of complementary and alternative medicine (CAM) in hypertensive patients of a tertiary care center in India. Int J Clin Pharmacol Ther 41(7): 294-298.

26. Osamor PE, Owumi BE (2010) Complementary and alternative medicine in the management of hypertension in an urban Nigerian community. BMC Complement Altern Med 10(1): 36.

27. Wang CZ, Mehendale SR, Yuan CS (2007) Commonly used antioxidant botanicals: active constituents and their potential role in cardiovascular illness. The American journal of Chinese medicine 35(4): 543-558.

28. Mansoor GA (2001) Herbs and alternative therapies in the hypertension clinic. Oxford University Press 14(9): 971-975.

29. Hasan SS (2009) Use of complementary and alternative medicine among patients with chronic diseases at outpatient clinics. Complement Ther Clin Pract 15(3): 152-157.

30. Tachjian A, Maria V, Jahangir A (2010) Use of herbal products and potential interactions in patients with cardiovascular diseases. J Am Coll Cardiol 55(6): 515-525.

31. Silagy CA, Neil H (1994) A meta-analysis of the effect of garlic on blood pressure. J Hypertens 12(4): 463-468.

32. Nakao M, Yano E, Nomura S, Kuboki T (2003) Blood pressure-lowering effects of biofeedback treatment in hypertension: a meta-analysis of randomized controlled trials. Hypertens Res 26(1): 37-46.

33. Hutchinson S, Ernst E (2003) Yoga therapy for coronary heart disease: a systematic review. Focus on alternative and complementary therapies 8(1): 144-144.

34. Kaptchuk TJ, Eisenberg DM (1998) The persuasive appeal of alternative medicine. Ann Intern Med 129(12): 1061-1065.

35. Kessler RC, Davis RB, Foster DF, Rompay VMI, Walters EE, et al. (2001) Long-term trends in the use of complementary and alternative medical therapies in the United States. Annals of internal medicine 135(4): 262-268.

36. Egede LE, Ye X, Zheng D, Silverstein MD (2002) The prevalence and pattern of complementary and alternative medicine use in individuals with diabetes. Diabetes care 25(2): 324-329.

37. Chavez ML, Jordan MA, Chavez PI (2006) Evidence-based drug-herbal interactions. Life Sci 78(18): 2146-2157.

38. Hwang JH (2015) The use of complementary and alternative medicine by Korean breast cancer women: is It associated with severity of symptoms? Evidence-Based Complementary and Alternative Medicine pp. 7.

39. Robinson A, McGrail M (2004) Disclosure of CAM use to medical practitioners: a review of qualitative and quantitative studies. Complement Ther Med 12(2-3): 90-98.

40. Berger S, Braehler E, Ernst J (2012) The health professional-patientrelationship in conventional versus complementary and alternative medicine. A qualitative study comparing the perceived use of medical shared decision-making between two different approaches of medicine. Patient education and counseling 88(1): 129-137.

41. Jump J (1998) Physicians' attitudes toward complementary and alternative medicine. Integrative Medicine 1(4): 149-153.

42. Milden SP, Stokols D (2004) Physicians' attitudes and practices regarding complementary and alternative medicine. Behav Med 30(2): 73-84.

\section{Your next submission with Juniper Publishers will reach you the below assets}

- Quality Editorial service

- Swift Peer Review

- Reprints availability

- E-prints Service

- Manuscript Podcast for convenient understanding

- Global attainment for your research

- Manuscript accessibility in different formats

( Pdf, E-pub, Full Text, Audio)

- Unceasing customer service

Track the below URL for one-step submission

https://juniperpublishers.com/online-submission.php 